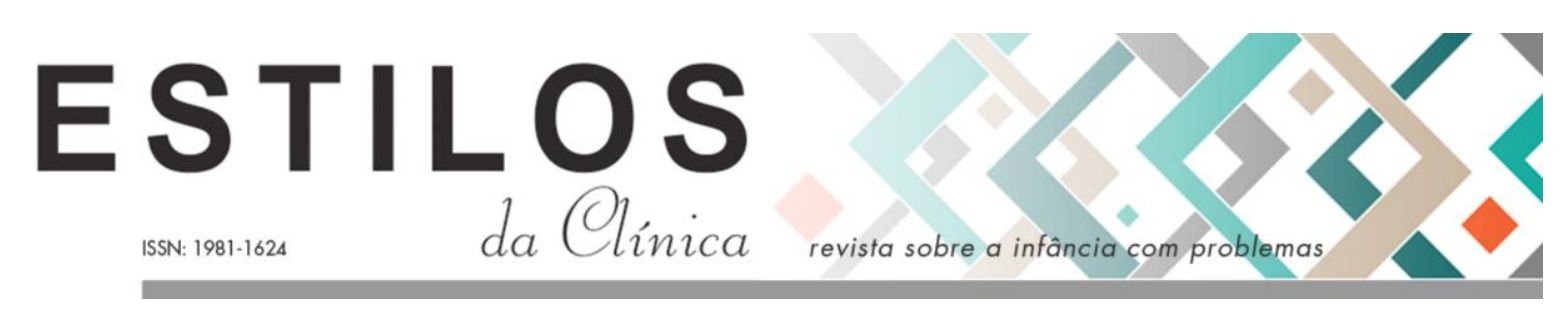

DOI: https://doi.org/10.11606/issn.1981-1624.v24i3p445-457.

Artigo

\title{
Acompanhamento Terapêutico Escolar: uma atuação caracterizada pelo "entre"
}

\author{
Verônica Gomes Nascimento; Adrielle de Matos Borges Teixeira; Aline de Almeida \\ Santos Spada; Maria Virgínia Machado Dazzani
}

Resumo. O presente artigo tem o objetivo de apresentar a atuação do Acompanhamento Terapêutico Escolar (ATE), sendo esta uma prática crescente, no contexto brasileiro, a qual encontra-se associada ao processo de efetivação da inclusão escolar. Mas o que caracteriza essa atuação? A partir da noção da inclusão como ato terapêutico, considera-se que a atuação é marcada por uma posição do estar "entre" (entre o estudante e o(s) outro(s)), elemento intrínseco à prática. Mas também revela certa indefinição, incertezas e instabilidades inerentes a esta posição. Diante disso, a intenção é refletir sobre tais questões e suas relações com um possível enquadre profissional.

Palavras chave: Acompanhamento Terapêutico; inclusão escolar; enquadre profissional.

\section{Acompañamiento Terapéutico Escolar: una actuación caracterizada por el "entre"}

Resumen. El presente artículo tiene el objetivo de presentar la actuación del Acompañamiento Terapéutico Escolar (ATE), siendo esta una práctica creciente, en el contexto brasileño, la cual se encuentra asociada al proceso de efectivización de la inclusión escolar. Pero ¿qué caracteriza esta actuación? A partir de la noción de la inclusión como acto terapéutico, se considera que la actuación es marcada por una posición de estar "entre" (entre el estudiante(s) y el otro(s)), elemento intrínseco a la práctica. Pero también revela cierta indefinición, incertidumbres e inestabilidades inherentes a esta posición. Ante ello, la intención es reflexionar sobre tales cuestiones y sus relaciones con un posible encuadre profesional.

Palabras claves: Acompañamiento Terapéutico; inclusión escolar; encuadre profesional.

\footnotetext{
*Doutoranda em Psicologia, Universidade Federal da Bahia (UFBA), Salvador, BA, Brasil. E-mail: veronica_gomes_nascimento@hotmail.com

**Doutoranda em Psicologia, Universidade Federal da Bahia (UFBA Salvador, BA, Brasil. E-mail: adriellematos@hotmail.com

***Mestre em Psicologia, Universidade Federal da Bahia (UFBA), Salvador, BA, Brasil. E-mail: alinealmeida.psi@gmail.com

****Doutora em Educação, Professora Associada do Instituto de Psicologia da Universidade Federal da Bahia (UFBA), Salvador, BA, Brasil. E-mail: vdazzani@gmail.com
} 


\section{Accompaniment Therapeutic School: a professional performance characterized by the "between"}

The purpose of this article is to present the performance of the School Therapeutic Accompaniment (STA), which is a growing practice in the Brazilian context, being associated with the process of inclusive education. But what characterizes this performance? From the notion of inclusion as a therapeutic act, it is considered that the performance is marked by a position of being "between" (between the student and the others), an intrinsic element to the practice. But it also reveals a certain lack of definition, uncertainties and instabilities inherent in this position. Given this, the intention is to reflect on such issues and their relationships with a possible professional setting. Keywords: Therapeutic Accompaniment; inclusive education; professional setting.

D esenvolvido originalmente como uma alternativa à prática dos asilos psiquiátricos, o Acompanhamento Terapêutico surgiu como um recurso que possibilitava a inclusão social a partir de um método que promovia a circulação dos usuários dos centros de saúde mental pelos diferentes espaços da vida pública. De acordo com Porto e Sereno (1991), o acompanhamento tinha por objetivo integrar a organização psíquica dos sujeitos à dinâmica social. Quando se considera o Acompanhamento Terapêutico com crianças, é notória a ênfase em um trabalho voltado para a socialização daquelas que apresentam sofrimento psíquico grave (Coelho, 2007). Como se sabe, um dos principais contextos de socialização infantil, na maioria das culturas contemporâneas, é a escola. Nesse sentido, considerando os movimentos sociais e políticos atuais - promotores de uma escola mais inclusiva -, a grande demanda do Acompanhamento Terapêutico com crianças ocorre no âmbito escolar e, por tal motivo, hoje se fala em Acompanhamento Terapêutico Escolar (ATE).

O que caracteriza essa atuação? Quais são as possibilidades e entraves dessa prática diante das demandas da inclusão escolar? Refletir sobre essas questões é uma ação necessária neste cenário, uma vez que a atuação do ATE tem sido uma prática crescente, sendo ainda marcada por certo grau de ambiguidade e falta de consenso. A partir de tais questionamentos, o presente artigo objetivou discutir o lugar do ATE enquanto dispositivo de intervenção que atua nas relações que são estabelecidas dentro da escola no âmbito da educação inclusiva. Para tanto, será apresentada uma breve contextualização sobre a inclusão escolar, seguida de ponderações sobre a inclusão como ato terapêutico e, por fim, algumas reflexões sobre o lugar do ATE diante dos desafios desse contexto.

\section{Inclusão escolar no Brasil: uma breve contextualização}

O Brasil foi palco de grande influência de movimentos internacionais significativos para alcançar uma perspectiva de educação inclusiva. A Unesco realizou, em 1990, a primeira ação com o propósito de refletir e discutir sobre a universalidade da educação. Houve uma Conferência Mundial sobre uma Educação para Todos, onde foram estabelecidos alguns objetivos, tais como a expansão da educação e a melhoria da qualidade do sistema educativo. Após um ano, o referido evento criou a Comissão Internacional sobre Educação para o Século XXI, a qual seria responsável pelas discussões sobre educação neste século (Abenhaim, 2005). 
Dessa forma, a Comissão Internacional sobre Educação para o Século XXI tinha como base dois princípios: 1) a educação é um direito de todos; 2) o ensino deve estar ao alcance de todos. A partir desse movimento, foi realizada, em 1994, a Conferência Mundial sobre Necessidades Educativas Especiais, na cidade de Salamanca, destacando a preocupação sobre o lugar das pessoas com necessidades educativas especiais (Abenhaim, 2005). A Declaração de Salamanca promoveu mudanças importantes nas áreas da política, da educação e das práticas relacionadas às necessidades educativas especiais (Spada, 2016).

A Declaração de Salamanca (Unesco, 1994) defende o princípio básico de que todas as escolas têm o dever de garantir a entrada de crianças com todos os tipos de necessidades educativas especiais. Além disso, o documento convoca às escolas para propiciarem espaços onde atitudes discriminatórias possam ser combatidas. Este documento constituiu um marco muito importante para o Brasil, pois movimentou as instâncias responsáveis pela educação para uma promoção de discussões e ações mais efetivas no que se refere ao ingresso das crianças com necessidades educativas especiais na escola.

Em 2006, foi elaborada a Convenção Internacional sobre os Direitos das Pessoas com Deficiência, sendo o texto promulgado pelo Brasil em 25 de agosto de 2009. No artigo 24, da Convenção sobre os Direitos das Pessoas com Deficiência (Decreto 6.949/2009), consta que "os Estados Partes reconhecem o direito das pessoas com deficiência à educação", sendo que estes devem assegurar o sistema educacional inclusivo em todos os níveis, assim como o aprendizado ao longo de toda a vida. Sendo assim, o referido documento explicita que os Estados Partes precisam assegurar, entre outros aspectos, que adaptações razoáveis de acordo com as necessidades individuais sejam providenciadas e que as pessoas com deficiência recebam o apoio necessário, no âmbito do sistema educacional geral, com vistas a facilitar sua efetiva educação. Além disso, medidas de apoio individualizadas e firmadas devem ser adotadas em ambientes que maximizem o desenvolvimento acadêmico e social, de acordo com a meta de inclusão plena.

O movimento político e social tem avançado no intuito de efetivar práticas inclusivas. Em 2012, foi instituída a Política Nacional de Proteção dos Direitos da Pessoa com Transtorno do Espectro Autista (TEA), através da Lei 12.764, a qual assegura a este público o direito ao acesso à educação e ao ensino profissionalizante, assim como à moradia, ao mercado de trabalho e à previdência social e à assistência social (Art. $\left.3^{\circ}, \mathrm{IV}\right)$.

Em 2015, foi instituída a Lei N ${ }^{\circ} 13.146 / 2015$ - Lei Brasileira de Inclusão da Pessoa com Deficiência (Estatuto da Pessoa com Deficiência). A LBI/2015 reúne propostas encontradas em documentos anteriores, reafirmando os compromissos já estabelecidos. O capítulo IV é dedicado ao direito à educação, no qual consta que "a educação constitui direito da pessoa com deficiência, assegurados sistema educacional inclusivo em todos os níveis e aprendizado ao longo de toda a vida, de forma a alcançar o máximo desenvolvimento possível de seus talentos e habilidades físicas, sensoriais, intelectuais e sociais, segundo suas características, interesses e necessidades de aprendizagem" (Art. 27).

O Art. 28 da LBI/2015 explicita a incumbência que deve ter o poder público em assegurar, criar, desenvolver, implementar, incentivar, acompanhar e avaliar certas medidas. Dentre tais medidas, consta a necessidade de ofertar um projeto pedagógico que institucionalize o atendimento educacional especializado, assim como os demais serviços e adaptações razoáveis, para atender às características dos estudantes com deficiência e garantir o seu pleno acesso ao currículo em condições de igualdade, promovendo a conquista e o exercício de sua autonomia (inciso III, Art. 28). 
Além disso, ainda de acordo com o referido documento, o poder público deve garantir a oferta de profissionais de apoio escolar, como consta no inciso XVII do Art. 28. O profissional de apoio escolar é pessoa que exerce atividades de alimentação, higiene e locomoção do estudante com deficiência e atua em todas as atividades escolares nas quais se fizer necessária, em todos os níveis e modalidades de ensino, em instituições públicas e privadas, excluídas as técnicas ou os procedimentos identificados com profissões legalmente estabelecidas (inciso XIII do Art. $3^{\circ}$ ).

É importante destacar que o documento apresenta a responsabilidade do poder público em garantir tais medidas. Entretanto, explicita, no $\S 1^{\circ}$ do Art. 28, que aplica-se, obrigatoriamente, às instituições privadas de qualquer nível e modalidade de ensino, o disposto em determinados incisos, como os que foram descritos referentes ao projeto pedagógico (inciso III) e a oferta do profissional de apoio escolar (inciso XVII). A LBI/2015 afirma, ainda, que é vedada a cobrança de valores adicionais nas mensalidades, anuidades e matrículas no cumprimento de tais determinações.

A Lei 12.764/2012 menciona que a pessoa com TEA, incluída nas classes comuns de ensino regular, tem direito a acompanhante especializado, em casos de comprovada necessidade (Parágrafo único, inciso IV, Art. $3^{\circ}$ ). Diante disso, observa-se que a garantia do direito a um acompanhamento especializado constitui um avanço significativo na direção da efetivação das práticas inclusivas. Entretanto, é possível levantar as seguintes questões: quem é esse acompanhante especializado? Seria um profissional de alguma área específica de conhecimento? Há uma formação exigida para esse acompanhante?

A oferta de profissional de apoio escolar (LBI/2015) e do acompanhante especializado (Lei 12.764/2012) revelam, de algum modo, uma preocupação social e política em garantir o suporte necessário e individualizado para os estudantes que apresentam alguma dificuldade no processo de escolarização. No entando, é fundamental mencionar que antes de tais propostas serem elaboradas e publicadas, o Acompanhamento Terapêutico Escolar (ATE) já mostrava suas intenções em contribuir para o desenvolvimento de uma educação inclusiva, tendo possibilidade de atuação sobretudo nas escolas privadas. Apesar das semelhanças entre as práticas desenvolvidas, observa-se que cada contexto escolar emprega uma terminologia para caracterizar a atuação, tais como: "acompanhante psicopedagógico", "acompanhante terapêutico", "monitor", "tutor" (Matos \& Diniz, 2014).

Quais seriam as diferenças entre o profissional de apoio escolar, o acompanhante especializado e o acompanhante terapêutico escolar? Considerando o que consta na LBI/2015, compreende-se que o profissional de apoio escolar é um profissional de nível médio, o qual deve trabalhar com demandas relativas à higiene, locomoção e alimentação. $\mathrm{O}$ acompanhante especializado (a partir da Lei 12.764) é responsável pela atuação junto a crianças com TEA no âmbito da inclusão no sistema regular de ensino. Não é possível identificar quais são especificidades da prática de tal profissional, ou seja, se ele seria responsável pelos cuidados básicos ou também pelo processo pedagógico. Mas fica claro que o profissional deve ser especializado (nas questões acerca do TEA), o que aponta para uma exigência importante. E o acompanhante terapêutico escolar, de forma geral (pois existem diferenças de práticas relacionadas ao contexto escolar ou leitura teórica do profissional), se responsabiliza por mediar o processo de inclusão escolar do estudante (Nascimento, 2015). Isso significa atuar na relação entre o estudante e os professores, colegas, funcionários, com o intuito de promover ações inclusivas em parceria com a escola. 
No cenário atual brasileiro, observa-se que o espaço profissional reservado aos acompanhantes terapêuticos escolares tem sido ocupado, na maioria dos casos, por estagiários (Matos \& Diniz, 2014). Os estagiários, de modo geral, são vinculados aos cursos de psicologia, pedagogia, mas há também profissionais de áreas como educação física e fisioterapia (Nascimento, 2015). Entretanto, de modo distinto, o acompanhante especializado, segundo Berenice Piana (autora de lei), não pode ser um estagiário, considerando que deve ser um especialista. Já o profissional de apoio escolar, como mencionado anteriormente, possui apenas o nível médio.

Diante disso, observa-se que são três caracterizações que possuem diferenças entre si, embora apresentem uma finalidade semelhante: o apoio no processo de inclusão escolar de estudantes com determinadas dificuldades. Mas apoiar como ? O estudante precisa de apoio em quais aspectos da sua experiência escolar? Talvez a tentativa de responder a tais questões nos direcione a escolha pelo profissional adequado, pois as demandas podem se diferenciar, por exemplo, em cuidados pessoais, aspectos pedagógicos e aspectos subjetivos. Vale salientar que os cuidados pessoais estão sendo destinados ao profissional de apoio escolar e os aspectos pedagógicos e subjetivos a um acompanhante especializado ou um acompanhante terapêutico escolar, entendendo que existem aproximações entre tais atuações, mesmo que apresentem diferenças quanto a formação exigida para o profissional.

Nesse sentido, considerando pelo menos a atuação do profissional de apoio escolar e do acompanhante terapêutico escolar, compreende-se que há uma diferença relativa às demandas que se apresentam. Desse modo, quando a demanda envolve os aspectos, sobretudo subjetivos (sem excluir os aspectos pedagógicos), entende-se que é fundamental que o trabalho seja exercido por um acompanhante terapêutico escolar, visto que esse conta com suporte teórico e de supervisão para o desenvolvimento da sua atuação.

Alguns estudantes que apresentam questões subjetivas graves, demonstram sérios impasses e dificuldades na experiência de escolarização, a qual envolve não apenas o ato de aprender, mas também de se relacionar com o outro, com as regras, etc. Diante disso, evidencia-se a importância de haver um mediador para auxiliar o estudante nessa relação com tudo o que se refere à instituição escolar. Tal mediador (acompanhante) atua para promover a autonomia do estudante e a implicação da instituição escolar no processo educativo do mesmo. Isso significa dizer que o acompanhante deixa de ser necessário, sobretudo quando se torna possível, para o sujeito, construir laço com o outro, com o social (Jerusalinsky, 2006), a partir dos indicativos de emergência subjetiva. Tal aspecto é o que caracteriza a condição intermitente e temporária da atuação.

\section{Inclusão Escolar como ato terapêutico: efeitos para o enlace e para a emergência subjetiva}

A partir das considerações elaboradas por Kupfer (1997; 2006), a inclusão escolar, ao contemplar aspectos subjetivos além dos políticos e sociais, pode ser considerada como um ato terapêutico. A autora pontua que a inclusão escolar revela efeitos terapêuticos no que se refere ao estabelecimento do laço social, no sentido da construção da relação com o outro. Kupfer (2006) desenvolveu a proposta de uma inclusão como ato terapêutico afirmando que se há um impedimento para a criança enodar com o Outro, levá-lo à trama social - às ruas, à escola, por exemplo - significa buscar e tratar o reordenamento simbólico do sujeito. 
Kupfer (2006) afirma que há uma aposta, com a inclusão, no poder subjetivante dos diversos discursos que circulam no interior do campo escolar. Segundo a autora, quando a escola dá um lugar à criança, faz uma atribuição, uma aposta imaginária de um lugar social, pois quem vai à escola recebe o estatuto de criança (Kupfer, 2006). Ao indicar um lugar social à criança, há uma atribuição, também, de um lugar de sujeito (Fráguas \& Berlinck, 2001). Jerusalinsky (2010) afirma que "escola é coisa de criança, no final das contas se esses meninos e meninas têm problemas, mas estão na escola, seus atos viram artes" (p. 151), revelando a importância do significante "escola" e, dessa forma, os efeitos terapêuticos que podem decorrer da circulação por esse espaço.

Assim, há uma ênfase nos efeitos terapêuticos produzidos no processo de inclusão escolar para a criança que apresenta impasses no processo de subjetivação (Kupfer, 2006). Pode ser muito delicado o estabelecimento do laço social para tais crianças, mas há uma circulação social possível, uma espécie de enlace, sendo a escola um espaço representativo e fundamental para efetivação de tal enlace (Albe \& Magarián, 1991, citado por Kupfer, 2006). Kupfer (2006) destaca, ainda, que os efeitos terapêuticos podem ser observados mesmo diante de uma escola que apresenta falências em diversos aspectos do ensino.

A perspectiva de uma inclusão como ato terapêutico está associada à proposta da educação terapêutica. Kupfer (1997) elaborou esta proposta, a qual reúne educar e tratar no trabalho realizado com as crianças com impasses subjetivos. A autora enfatiza que a educação terapêutica deve oferecer às crianças palavras e produção de cultura, códigos compartilhados para que algo de significante, de simbólico, possa advir. Por isso, a inclusão como ato terapêutico aponta para uma inclusão que vai além da escola, refere-se a uma inclusão no universo simbólico compartilhado, o qual servirá de empréstimo para o enlace das crianças como forma de circulação no social e de retomada da constituição subjetiva (Nascimento, 2015). O objetivo, conforme a análise de Nascimento (2015), é possibilitar um lugar para o sujeito emergir, para que suas produções possam ser vistas como singulares e representantes da sua história.

Diante disso, é importante pontuar que o "terapêutico", associado ao processo de inclusão, aponta para o sujeito, para o singular, para os efeitos da circulação social (Kupfer, 2006). Nascimento (2015) analisa que a inclusão considerada como um ato terapêutico não pode ser vista como uma ferramenta genérica, útil para todos, seguindo as mesmas estratégias, visto que está situada na observação do caso a caso. Segundo a autora, essa perspectiva de inclusão pode ser caracterizada como artesanal, pois direciona o olhar para o singular, para as demandas de cada um, demarcando um manejo que deve apresentar um cuidado particular. A educação deveria, de acordo com Silva (2014), reivindicar seu caráter artesanal a despeito das exigências globais. Dessa forma, Silva (2014) destaca a importância da existência, no campo educativo, de um trabalho artesanal, não serial, um trabalho realizado para cada um. Nascimento (2015) enfatiza, no entanto, que tal perspectiva artesanal não deve perder de vista o que está no contorno social, pois precisa ser considerada, também, como ato político, adentrando as políticas inclusivas.

Cabe destacar que o entendimento da inclusão escolar como ato terapêutico não subordina o campo educacional às finalidades da saúde mental. A Educação constitui um direito social e político que permite o pleno exercício da cidadania, sendo pressuposto básico para o exercício de todos os outros direitos (Cury, 2002). Deste modo, nessa proposta, a escola não perde o seu caráter de compartilhamento do patrimônio cultural da humanidade. Além disso, considera-se que a instituição educativa é convocada a repensar suas práticas a partir da inclusão escolar de 
crianças com deficiências, como destaca Spada (2016). Segundo a autora, a escola exerce um papel fundamental como agente catalisador e constituinte da subjetividade dessas crianças.

Jerusalinsky (2006) afirma que a escola precisa inscrever a criança em um projeto maior de transmissão da cultura, além dos projetos pedagógicos (Jerusalinsky, 2006). Segundo Mena (2000), a cultura possui elementos constitutivos para a construção da subjetividade, pois é por meio destes que cada um se sente representante da sociedade. $O$ autor explicita que existe uma "inclusão simbólica", a qual revela "a autorização e permissão para que os elementos culturais sejam compartilhados por todos, e através desse compartilhamento, possam ser reconhecidos como pertencentes, integrantes e representantes da cultura" (p. 38).

\section{Acompanhamento Terapêutico Escolar: características da atuação, o "entre" e seus impasses}

O Acompanhamento Terapêutico Escolar é pensado, neste artigo, a partir da perspectiva da inclusão escolar como ato terapêutico, considerando o estabelecimento do laço social, o investimento no sujeito e a atenção aos efeitos terapêuticos envolvidos em todo processo inclusivo. De modo geral, o acompanhante terapêutico é convidado a atuar como um mediador entre a criança e os desafios que lhes são apresentados. Esta modalidade de atuação tem sido utilizada pelas escolas como estratégia para viabilizar o processo de inclusão e permitir que o estar na escola não seja tão custoso para a criança (Matos \& Diniz, 2014).

Algumas atribuições compatíveis com a atuação deste profissional foram levantadas por Duk (2006), quando esta autora reflete sobre a importância do profissional de apoio no processo inclusivo: participar na elaboração do programa e nas flexibilizações curriculares necessárias a determinados alunos; nas adaptações do material didático; na elaboração e planejamento de diferentes estratégias de ensino; no esclarecimento das necessidades educacionais especiais de alunos com problemas de aprendizagem; no apoio aos alunos; no atendimento contínuo na sala de aula; no apoio fora da sala de aula; e no apoio aos pais.

A importância do acompanhante enquanto um mediador fica evidente quando se considera a concepção vygostskyana de mediação. Conforme Matos e Diniz (2014), ao mediar a relação do aluno com os conhecimentos formais e informais da escola e, para além disso, as relações que a criança estabelece dentro deste contexto, o acompanhante está propiciando não somente a aprendizagem, mas também a formação da consciência dos estudantes. Nesta perspectiva, os instrumentos servem como mediadores entre o sujeito e o mundo, auxiliando no aprendizado do chamado material cultural, que ocorre de um nível interpsicológico para outro intrapsicológico. O acompanhante funciona, muitas vezes, como um instrumento que realiza essa mediação.

Pode-se pensar, desse modo, que o acompanhante terapêutico escolar ocupa um lugar "de fronteira", o qual embora possibilite a incerteza e insegurança decorrentes de não se estar numa posição consolidada, é o que marca a atuação do ATE. Nascimento, Silva e Dazzani (2015) ampliam esta discussão, ao considerarem que o acompanhante trabalha no lugar do "entre", isto é, entre a criança e as outras crianças, entre a criança e o professor, entre a criança e a família. Nesse sentido, este lugar, incerto e instável, é justamente o lugar em que o acompanhante pode contribuir para o desenvolvimento da criança e para o processo inclusivo desta, abrindo possibilidades para o estabelecimento do laço social.

Entretanto, uma pesquisa realizada por Anderson et al. (2005 citado por Sanini, Sifuentes \& Bosa, 2013) indicou que a presença de um adulto na sala (com exceção do professor) poderia 
se constituir como obstáculo para o processo inclusivo. Isto decorreria do afastamento das outras crianças do contato com esse adulto e isso, por sua vez, ocasionaria a redução do contato destas com a criança acompanhada. É preciso considerar, contudo, como tem ocorrido a prática do acompanhante analisado nesse estudo para uma maior contextualização da reflexão proposta. Spada (2016), refletindo sobre a pesquisa realizada por Anderson et al., pontua que é necessário observar a atuação do profissional, sua formação e os objetivos de sua prática, visto que a simples presença de outro adulto na sala de aula não poderia representar uma dificuldade para o processo de inclusão, mas sim uma prática sem embasamento teórico e distante dos parâmetros éticos referentes a uma efetiva proposta inclusiva. Dessa forma, uma atuação que se pauta no "entre", isto é, nas relações, implica por si só na relação deste profissional com as crianças e demais atores escolares. Se o profissional está atuando na relação, como poderia representar um obstáculo?

Outro ponto que merece ser destacado diz respeito à relação com o professor. Conforme Kupfer e Petri (2000), o acompanhante pode auxiliá-lo na compreensão da singularidade da criança, promovendo um olhar ampliado para além da função pedagógica. Além disso, esse profissional pode contribuir com a atuação do professor e demais atores escolares ao possibilitar a percepção dos avanços da criança que ultrapassam a dimensão das aprendizagens formais.

\section{Algumas especificidades e impasses da atuação}

Nascimento, Silva e Dazzani (2015) destacam que o acompanhante terapêutico escolar não é um profissional específico de um determinado campo ou de uma abordagem teórica. Profissionais de Psicologia, Educação, Fisioterapia, Terapia Ocupacional, dentre outras áreas, têm contribuído para a realização do ATE a partir de perspectivas metodológicas distintas. Nessa perspectiva, Matos e Diniz (2014) realizaram uma pesquisa em que se buscou reconhecer a voz dos acompanhantes, escutando suas percepções sobre o trabalho que realizam. Utilizando a aplicação de questionários com acompanhantes terapêuticos escolares, as autoras constataram que houve uma divergência de opiniões sobre alguns pontos relativos a demandas contratuais/institucionais, com ênfase na realização de contratos precários de trabalho. Também foram evidenciadas discordâncias sobre as práticas realizadas e mesmo sobre as concepções do que seja educação inclusiva e qual o papel do acompanhante nesse processo. Esse quadro demonstra diferentes visões e falta de consenso existente sobre tal tópico e, de forma mais ampliada, indica um lugar ainda indefinido ocupado pelo ATE na Educação Inclusiva.

Salienta-se ainda na pesquisa de Matos e Diniz (2014) a reflexão sobre um "ciclo vicioso" que tem envolvido as práticas desse profissional. Pôde-se constatar nos dados coletados pelas autoras, que os participantes eram, em sua maioria, recém-formados ou com poucos anos de prática e que, em geral, começaram a atuar como acompanhantes ainda sendo estagiários de psicologia. Esse contexto revela que, para muitos, o ATE surge como possibilidade de ingressar no mercado de trabalho; porém, como tem se apresentado um quadro de desvalorização profissional, com baixas remunerações e sem direitos trabalhistas, esses estagiários deixam o ATE justamente quando se tornam mais experientes e possuem condições de ter perspectivas de trabalho que oferecem um retorno financeiro e profissional mais satisfatório.

Com isso, o ATE volta a ser praticado por recém-formados e estagiários. Faz-se importante destacar que os acompanhantes estagiários ou recém-formados desenvolvem uma prática importante para o processo inclusivo dos estudantes, visto que apresentam uma postura de curiosidade e interesse pela nova experiência. Dessa forma, estes acompanhantes avançam em 
suas trajetórias profissionais e também produzem avanços para a área. Porém, quando se pensa na consolidação da atuação do ATE e considerando que o desenvolvimento científico ocorre com a acumulação de experiências e de conhecimentos, as autoras questionam como o campo poderá se desenvolver, dado que o ciclo permanece o mesmo.

\section{Função e efeitos da atuação}

Considerando o fato de que o ATE pode ser realizado por distintos profissionais e através de diferentes tipos de contratação profissional, cabe salientar que existem diversas formas de atuação dentro da área caracterizada. Defende-se aqui a perspectiva segundo a qual a inclusão é considerada um ato terapêutico. Dessa forma, a atuação do ATE deve ser entendida, também, como ato terapêutico, tomando a possibilidade que se presentifica no contexto escolar de estabelecimento do laço social - ou do enlace (Albe \& Magarián, 1991, citado por Kupfer, 2006) - e o olhar direcionado para o singular, contemplando os aspectos subjetivos envolvidos no processo inclusivo e a emergência do sujeito.

Nesse sentido, Fráguas e Berlinck (2001) afirmam que o acompanhante atua em uma posição de "entre" - entre o pedagógico e o terapêutico. Na mesma direção, Melão (2008), ao descrever sua própria experiência enquanto acompanhante terapêutica escolar, afirma as incertezas que envolvem este lugar, pois, trata-se de um lugar "entre" a psicanálise e a educação e que, deste modo, não está muito bem delimitado.

Partindo da análise de uma experiência de ATE com uma criança autista, Nascimento, Silva e Dazzani (2015) refletiram que, no caso analisado, as intervenções do acompanhante possibilitaram efeitos significativos para as interações sociais do estudante acompanhado, inclusive contribuindo para a utilização da fala como recurso comunicativo e para a emergência do sujeito. Neste caso, percebe-se que a atuação do acompanhante foi além da promoção do processo inclusivo, desdobrando-se pelo desenvolvimento e constituição psíquica do sujeito acompanhado. Estes autores ressaltam que essa modalidade de intervenção tem se mostrado eficiente nas práticas inclusivas quando estão direcionadas para as relações construídas no contexto escolar. Ademais, promovem efeitos terapêuticos, contribuindo com a retomada da constituição subjetiva.

Segundo Assali, Abbamonte e Amâncio (1999), o acompanhante significa, para a criança, suas iniciativas, convocando-a para a rotina e para a existência de regras, envolvendo-a, assim, em um contexto social e educacional. Ao supor a existência de um sujeito, este profissional está produzindo um efeito terapêutico. Montellano et al. (2009) consideram que o acompanhante cumpre a função de interpretar e traduzir as diversas linguagens da criança e de funcionar como um espelho que a possibilite se reconhecer. Com isso, percebe-se que está atuando no lugar do "entre", ao passo em que contribui para a afirmação da sua identidade.

Para Sereno (2006), o acompanhante nomeia e fornece sentido ao que a criança vai vivenciando e se faz importante que apresente uma posição "invisível", isto é, que remeta ao outro a função que lhe cabe. Assim, a atuação do acompanhante estimula e convoca os professores e funcionários, por exemplo, a se relacionarem diretamente com o aluno, contribuindo com a autonomia tanto da criança quanto dos demais atores escolares. Para esta autora, o ATE deve ser concluído quando a turma, isto é, professor e alunos, se constituem como referência para a criança com impasses no processo de escolarização e, da mesma forma, esta se torna capaz de se comprometer com a turma. É fundamental acrescentar que os aspectos 
subjetivos envolvidos no processo e o modo como a criança se apresenta enquanto sujeito devem ser levados em consideração no momento da saída do acompanhante.

A partir do que foi exposto, é possível perceber que a perspectiva assumida envolve uma atuação que contempla e articula aspectos pedagógicos e terapêuticos, isto é, aspectos do contexto da educação e da escola e aspectos subjetivos. Na concepção da inclusão como ato terapêutico, sem desconsiderar a função social e pedagógica da instituição educativa, surge a necessidade de atentar para ambos os aspectos - terapêutico e pedagógico -, caracterizando uma atuação que se posiciona no "entre". É importante mencionar ainda que sem um posicionamento intermediário entre tratar e educar não se poderia falar em uma educação terapêutica, não haveria inclusão escolar como ato terapêutico. Assim, torna-se necessária a mediação entre o estudante e a instituição educativa, no sentido de facilitar a articulação entre tais aspectos.

Retomando o lugar do acompanhante em sua atuação, discutido anteriormente a partir de Nascimento, Silva e Dazzani (2015), é possível resgatar que este se posiciona "entre" a criança e os outros (professores, funcionários, outras crianças, família etc). Nascimento (2015) aponta alguns impasses vivenciados pelo acompanhante terapêutico escolar nesse lugar do "entre". A autora elaborou um texto a partir da sua experiência e revela que o acompanhante observa sua atuação "entre o subjetivo e o pedagógico; entre a sustentação do desejo e as regras sociais/escolares; entre o 'sair da sala' e o 'ficar no grupo'; entre o 'não pode' e a flexibilidade" (p. 91).

Dessa forma, observa-se que a atuação é marcada por uma posição do "entre" em diversos sentidos. Tal posição mostra-se como um elemento intrínseco à atuação do ATE e fundamental para a prática no sentido da inclusão como ato terapêutico. Porém, é uma posição que expressa também certa indefinição. A partir disso, é muito importante pensar e avançar as discussões sobre a atuação do ATE, pois, a posição do "entre" pode também refletir na consolidação deste lugar de atuação. Isso porque a indefinição pode se traduzir em um trabalho que pode ser desenvolvido de qualquer forma pelo profissional. E ainda, sem as condições trabalhistas necessárias.

Surge, então, essa questão: um lugar do "entre", junto com as incertezas e instabilidades inerentes a esta posição, isto é, a indefinição de estar "entre", poderia estar influenciando no modo como a atuação se efetiva e nas condições trabalhistas para o exercício do ATE? Esta é uma questão importante, visto que é preciso levar em conta que são duas condições do "entre" que apontam para dimensões diferentes: uma se refere a um lugar de atuação nas relações, um lugar de mediação (entre a criança e os outros, mas também entre o pedagógico e o terapêutico), marcado pelo investimento no laço social, considerando os aspectos subjetivos envolvidos nesse processo; a outra aponta para condições objetivas e estruturais para que esse trabalho seja realizado. Talvez seja possível caminhar para que as condições de trabalho sejam asseguradas, sem que a atuação deixe de assumir certa indefinição como uma marca da prática, assim como as incertezas e os impasses inerentes à própria experiência humana quanto ao que se refere ao ato de se relacionar.

\section{Considerações finais}

É indiscutível o avanço nas políticas voltadas para a inclusão escolar, mas estas não garantem que a mesma se efetive de modo a contemplar todos os aspectos envolvidos no processo inclusivo. Neste artigo, foi apresentada a perspectiva da inclusão como ato terapêutico, 
levando em consideração que é fundamental observar os aspectos subjetivos inerentes ao processo, visto que os estudantes com impasses no processo de escolarização podem apresentar fragilidades no encontro com o outro. A inclusão escolar revela-se, então, como a grande possibilidade da criança/adolescente se deparar e se relacionar com o outro (seus pares e com os adultos).

Como já mencionado anteriormente, o Acompanhamento Terapêutico Escolar mostra-se como uma ferramenta de mediação no processo inclusivo e atua no sentido de contemplar os aspectos subjetivos, considerando os efeitos terapêuticos que se revelam no contexto e nas relações escolares e abrindo espaço para emergência do sujeito. Deste modo, o acompanhante se posiciona no "entre", entre o estudante e os outros. O "entre" caracteriza também uma atuação que se situa entre o pedagógico e o terapêutico. Além disso, o acompanhante se depara com diversas situações nas quais se percebe entre uma possibilidade de intervenção e outra. E assim, se observa, muitas vezes em um impasse.

Tais considerações sobre o "entre" indicam que a atuação é marcada por uma indefinição, uma falta de delimitação do que pode ser realizado, o que pode dificultar o processo de consolidação da prática profissional do acompanhante. Porém, o "entre" representa a marca do ATE, no sentido de uma atuação de mediação voltada para o laço social. E a indefinição pode ser vista como uma característica inerente à atuação, a qual permite ao acompanhante partir do sujeito e não de intervenções definidas antecipadamente.

Diante disso, compreende-se que a atuação do ATE possui características gerais, mas se revela como uma atuação do "entre", marcada por indefinições e incertezas, as quais possibilitam que a direção seja tomada a partir do sujeito. Por isso, um enquadre profissional seria importante, e mostra-se urgente, mas um enquadre que abra espaço para o singular. $\mathrm{O}$ acompanhante, atuando no "entre", pode trabalhar contribuindo para que a criança/adolescente ingresse na escola, adentre no laço social e seja contemplado nas políticas públicas para educação. Espera-se, portanto, que os pontos aqui destacados possam promover a continuação do debate, na expectativa de uma atuação profissional comprometida eticamente com o sujeito.

\section{Referências}

Abenhaim, E. (2005). Os caminhos da inclusão: breve histórico. In: A. M. Machado, A. J. Veiga Neto, M. M. B. J. Neves, M. V. O. Silva, R. G. Prieto, W. Ranña, \& E. Abenhaim. (Orgs.). Psicologia e direitos humanos: educação inclusiva, direitos humanos na escola (pp. 39-53). São Paulo, SP: Casa do Psicólogo.

Assali, A. M., Rizzo, C., Abbamonte, R. M., \& Amâncio, V. (1999). O acompanhamento terapêutico na inclusão de crianças com distúrbios globais do desenvolvimento. $A$ psicanálise e os impasses da educação: Anais do Colóquio do Lugar de Vida, 114-121. São Paulo.

Brasil. Presidência da República. Secretaria de Direitos Humanos - SDH. Secretaria Nacional de Promoção dos Direitos da Pessoa com Deficiência - SNPD. Novos Comentários à Convenção sobre os Direitos das Pessoas com Deficiência. Brasília, 2014. Disponível em http://www.pessoacomdeficiencia.gov.br/app/sites/default/files/publicacoes/convencaosdpcd-novos-comentarios.pdf.

Brasil. Presidência da República. Casa Civil. Subchefia para Assuntos Jurídicos. Lei No 12.764, de 27 de dezembro de 2012. Política Nacional de Proteção dos Direitos da Pessoa com 
Transtorno do Espectro Autista. Brasília. Disponível em http://www.planalto.gov.br/ccivil_03/_ato2011-2014/2012/lei/112764.htm.

Brasil. Presidência da República. Casa Civil. Subchefia para Assuntos Jurídicos. Lei No 13.146, de 6 de julho de 2015. Lei Brasileira de Inclusão da Pessoa com Deficiência (Estatuto da Pessoa com Deficiência). Brasília. Disponível em http://www.planalto.gov.br/ccivil_03/_Ato2015-2018/2015/Lei/L13146.htm.

Coelho, C. F. de M. (2007) Convivendo com Miguel e Mônica: uma proposta de Acompanhamento Terapêutico de crianças autistas. Dissertação de mestrado, Instituto de Psicologia, Universidade de Brasília, Brasília. Disponível em http://repositorio.unb.br/handle/10482/3095? mode=full.

Cury, C.R.J. (2002). Direito à educação: direito à diferença. Cadernos de Pesquisa, 116, 245 262. doi: 10.1590/S0100-15742002000200010.

Declaração de Salamanca (1994). Conferência Mundial sobre Necessidades Educativas Especiais. Salamanca/Espanha: UNESCO.

Duk, C. (2006) Educar na Diversidade - material de formação docente. $3^{\text {a }}$ ed. Brasília: [MEC, SEEESP].

Fráguas, V., \& Berlinck, M. T. (2001). Entre o pedagógico e o terapêutico. algumas questões sobre o acompanhamento terapêutico dentro da escola. Estilos da Clínica 6 (11), 7-16. doi: https://doi.org/10.11606/issn.1981-1624.v6i11p7-16.

Jerusalinsky, A. (2010). Psicanálise e desenvolvimento infantil: um enfoque transdisciplinar 5a ed. Porto Alegre, RS: Artes e Ofícios.

Jerusalinsky, J. (2006). O acompanhamento terapêutico e a construção de um protagonismo. Escritos da criança, (6), 163-178. Porto Alegre, RS: Centro Lydia Coriat.

Kupfer, M. C. M. (1997). Educação Terapêutica: o que a psicanálise pode pedir à educação. Estilos da Clínica 2 (2), 53-61. doi: https://doi.org/10.11606/issn.1981-1624.v2i2p53-61

Kupfer, M. C. M. (2006). Duas notas sobre a inclusão escolar. Escritos da criança, (6), 71-81. Porto Alegre, RS: Centro Lydia Coriat.

Kupfer, M. C., \& Petri, R. (2000). "Por que ensinar a quem não aprende?”. Estilos da Clínica: 5(9),109-117. doi: https://doi.org/10.11606/issn.1981-1624.v5i9p109-117

Matos \& Diniz, A. (2014). Acompanhamento terapêutico e educação inclusiva: a voz dos ATs. In R. C. S. Souza, M. A. G. Bordas, \& C. S. Santos (Orgs.). Formação de professores e cultura inclusiva (pp. 45-66). São Cristovão, SE: UFS.

Melão, M. S. (2008) A escrita e a constituição do sujeito: um caso de autismo. Estilos da Clínica, 13 (25), 94-117. doi: https://doi.org/10.11606/issn.1981-1624.v13i25p94-117.

Mena, L. F. B. (2000). Inclusões e inclusões: a inclusão simbólica. Psicologia: Ciência e Profissão, 20(1), 30-39. doi: http://dx.doi.org/10.1590/S1414-98932000000100005.

Montellano, C. P., Nero, C. T., Sereno, D., Garfunkel, J. L., Vicentin, M. C. G., Almeida, M. N. C., \& Navarro, N. C. (2009). Construindo modos de ação na interface saúde-educação. In A. A. Anache, \& I. R. Silva (Orgs.). Educação inclusiva: experiências profissionais em psicologia (pp. 53- 68). Brasília, DF: CFP.

Nascimento (2015). O acompanhamento terapêutico escolar no processo de inclusão de uma criança autista. Dissertação de Mestrado, Universidade Federal da Bahia, Salvador, BA. Disponível em https://repositorio.ufba.br/ri/handle/ri/19009. 
Nascimento; Silva, A.; Dazzani (2015). Acompanhamento terapêutico escolar e autismo: caminhos para a emergência do sujeito. Estilos da Clínica, 20 (3), 520-534. doi: http://dx.doi.org/10.11606/issn.1981-1624.v20i3p520-534.

Porto, M. \& Sereno, D. (1991) Sobre Acompanhamento Terapêutico. In Equipe de Acompanhantes Terapêuticos do Hospital-Dia A Casa (Orgs.), A rua como espaço clínico: Acompanhamento Terapêutico. São Paulo, SP: Escuta.

Sanini, C., Sifuentes, M. \& Bosa, C. A. (2013). Competência social e autismo: o papel da brincadeira no contexto da brincadeira com pares. Psicologia Teoria e Pesquisa, 29 (1), 99105.doi: http://dx.doi.org/10.1590/S0102-37722013000100012.

Silva, K. C. B. (da) (2014). Educação inclusiva: para todos ou para cada um? Alguns paradoxos (in)convenientes. Tese de doutorado. Universidade de São Paulo, São Paulo, SP. Disponível em http://www.teses.usp.br/teses/disponiveis/48/48134/tde-29092014134527/pt-br.php.

Spada (2016) Inclusão escolar de crianças diagnosticadas com Transtorno do Espectro Autista: significados e práticas. Dissertação de mestrado, Universidade Federal da Bahia, Salvador, BA. Disponível em https://repositorio.ufba.br/ri/handle/ri/20228.

Sereno, D. (2006). Acompanhamento terapêutico e Educação Inclusiva. Psyche, 10(18), 167 179. Recuperado de http://pepsic.bvsalud.org/scielo.php?script=sci_arttext\&pid=S141511382006000200016. 